Rev. Saude públ., S. Paulo

7:381-8, 1973, 1973.

\title{
ALEITAMENTO NO PRIMEIRO ANO DE VIDA DE CRIANÇAS INTERNADAS EM HOSPITAL ASSISTENCIAL DO MUNICIPIO DE SÃO PAULO, BRASIL *
}

Rosenburg, O. - Aleitamento no primeiro ano de vida de crianças internadas em hospital assistencial do municipio de São Paulo, Brasil. Rev. Saúde públ., S. Paulo, 7:381-8, 1973.

Resumo: Estudo do tipo de aleitamento de 667 e 249 crianças internadas num hospital assistencial do municipio de São Paulo, Brasil, em 1969 e 1972, respectivamente, revelou uma queda do aleitamento natural exclusivo no primeiro ano de vida, de 5,85\% em 1969 para $3,61 \% \mathrm{em} 1972$, e do aleitamento misto, de $5,55 \%$ para $4,42 \%$. No primeiro semestre de vida, a queda no aleitamento natural exclusivo foi de 6,69\% em 1969 para 4,81\% em 1972, o mesmo se verificando no aleitamento misto. Em 1969, o aleitamento natural exclusivo caiu de $23,21 \%$ no primeiro mês para $4,06 \%$ no segundo mês, e em 1972 , de $23,07 \%$ no primeiro mês para $3,33 \%$ no segundo mês. A frequência do aleitamento artificial por leite em pó subiu de $81,11 \%$ em 1969 para 82,33\% em 1972.

Unitermos: Aleitamento *; Hospital pediátrico *; Hospital assistencial *.

\section{N T RODU Q A O}

Nesta pesquisa, procurou-se focalizar um dos aspectos mais importantes da alimentação no $10^{\circ}$ ano de vida, ou seja, o tipo de aleitamento em crianças internadas num hospital pediátrico de caráter assistencial do Município de São Paulo.

Com essa finalidade, levantaram-se dados sobre o tipo de aleitamento a que eram submetidos os lactentes internados no Hospital Infantil Menino Jesus, segundo informações prestadas pela mãe ou acompanhante do paciente, no momento da internação.

\section{POPULACAO E METODOS}

Fez-se o registro de dados sobre 0 aleitamento, anotados no momento da admissão, e obtidos de 667 e 249 crianças internadas por todas as causas, no decorrer dos anos de 1969 e 1972, respectivamente.

Foram excluídos do estudo os pron-

- Da Disciplina de Higiene da Criança do Departamento de Prática de Saúde Pública da Faculdade de Saúde Pública da USP. - Av. Dr. Arnaldo, 715 - Såo Paulo, SP - Brasil. 
ROSENBURG, O. - Aleitamento no primeiro ano de vida de crianças internadas em hospital assistencial do municíplo de São Paulo, Brasil. Rev. Saúde públ., S. Paulo, 1:381-8, 1973.

tuários dos filhos de funcionários municipais, crianças essas que recebem igualmente assistência no hospital em questão, por se tratar de pacientes de padrão sócio-econômico diferente.

Os dados obtidos foram agrupados sob 5 itens:

1) aleitamento natural;

2) aleitamento misto (leite materno + leite de vaca fresco ou em pó);

3) aleitamento por leite de vaca fresco;

4) aleitamento por leite em pó;

5) outros tipos de aleitamento (leite de vaca + leite em pó, ou produtos à base de soja).

\section{RESULTADOS}

O exame da Tabela 1 , referente ao tipo de aleitamento de 0 - 12 meses, mostra, de maneira geral, que o aleitamento natural, mesmo no primeiro mês de vida, em que ele comparece em percentual mais elevado $(23,21 \%)$, atinge proporções muito reduzidas em relação à alimentação artificial de todos os tipos. $\mathbf{E}$ essa inferioridade se acentua bruscamente logo depois do primeiro mês, portanto, em época muito precoce, e cai a níveis desprezíveis no segundo semestre de vida.

T A B EL A 1

Número e porcentagem de crianças no $10^{\circ}$ ano de vida, segundo tipo de aleitamento, no Hospital Menino Jesus - Município de Sáo Paulo em 1969.

\begin{tabular}{|c|c|c|c|c|c|c|c|c|c|c|c|c|c|}
\hline \multirow{2}{*}{\multicolumn{2}{|c|}{$\begin{array}{l}\text { meses } \\
\text { Idade }\end{array}$}} & \multicolumn{2}{|c|}{$\begin{array}{c}\text { Aleitamento } \\
\text { natural }\end{array}$} & \multicolumn{2}{|c|}{$\begin{array}{c}\text { Aleitamento } \\
\text { misto }\end{array}$} & \multicolumn{2}{|c|}{$\begin{array}{l}\text { Leite de } \\
\text { vaca }\end{array}$} & \multicolumn{2}{|c|}{$\begin{array}{l}\text { Leite em } \\
\text { pó }\end{array}$} & \multicolumn{2}{|c|}{ Outros } & \multicolumn{2}{|c|}{ Total } \\
\hline & & N.o & $\%$ & N. ${ }^{\circ}$ & $\%$ & N. ${ }^{\circ}$ & $\%$ & N.o & $\%$ & N.o & $\%$ & N.0 & $\%$ \\
\hline $01-$ & 1 & 26 & 23,21 & 6 & 5,36 & 2 & 1,79 & 78 & 69,64 & 一 & - & 112 & 100 \\
\hline $11-$ & 2 & 5 & 4,06 & 12 & 9,76 & 6 & 4,88 & 100 & 81,30 & $\ldots$ & 一 & 123 & 100 \\
\hline $21-$ & 3 & 2 & 1,85 & 8 & 7,41 & 9 & 8,33 & 87 & 80,56 & 2 & 1,85 & 108 & 100 \\
\hline $31-$ & 4 & 1 & 1,28 & 3 & 3,85 & 3 & 3,85 & 71 & 91,02 & - & - & 78 & 100 \\
\hline $41-$ & 5 & 1 & 1,76 & 5 & 8,77 & - & - & 51 & 89,47 & - & - & 57 & 100 \\
\hline $51-$ & 6 & - & - & 1 & 2,22 & 5 & 11,11 & 37 & 82,22 & 2 & 4,45 & 45 & 100 \\
\hline $61-$ & 7 & 1 . & 2,44 & 1 & 2,44 & 1 & 2,44 & 38 & 92,68 & - & - & 41 & 100 \\
\hline $71-$ & 8 & - & - & - & - & 4 & 10,81 & 32 & 86,49 & 1 & 2,70 & 37 & 100 \\
\hline $81-$ & 9 & 一 & - & - & - & 6 & 21,43 & 21 & 75,00 & 1 & 3,57 & 28 & 100 \\
\hline $91-$ & 10 & 1 & 5,56 & - & - & 2 & 11,11 & 14 & 77,77 & 1 & 5,56 & 18 & 100 \\
\hline $101-$ & 11 & 1 & 8,33 & 1 & 8,33 & 4 & 33,33 & 6 & 50,00 & - & - & 12 & 99,99 \\
\hline 11 & 12 & 1 & 12,50 & 一 & - & 1 & 12,50 & 6 & 75,00 & - & - & 8 & 100 \\
\hline TOTA & & 39 & $\mathbf{5 , 8 5}$ & 37 & 5,55 & 43 & 6,44 & 541 & 81,11 & 7 & 1,05 & 667 & 100 \\
\hline
\end{tabular}


ROSENBURG, O. - Aleitamento no primeiro ano de vida de crianças internadas em hospital assistencial do municíplo de Săo Paulo, Brasil. Rev. Saúde públ., s. Paulo, 7:381-8, 1973.

Um exame mais detalhado revela:

a) preponderância do aleitamento artificial de todos os tipos, com $\mathbf{8 8 , 6 0 \%}$ $(6,44 \%+81,11 \%+1,05 \%)$ sobre a soma do aleitamento natural $(5,85 \%)$ e do aleitamento misto $(5,55 \%)$, com total igual a $11,40 \%$;

b) inferioridade marcante do aleitamento natural exclusivo $(5,85 \%)$ em relação à soma de todos os tipos de aleitamento artificial $(88,60 \%)$ e de aleitamen- to misto $(5,55 \%)$, com total igual a 94,15\%;

c) preponderância do aleitamento artificial por leite em pó $(81,11 \%)$ sobre todos os outros tipos de aleitamento artificial: leite de vada $(6,44 \%)$ e outros $(1,05 \%)$.

Quanto à Tabela 2, no que se refere ao aleitamento entre $0 \backslash-6$ meses, os resultados foram os seguintes:

TABEL 2

Número e porcentagem de crianças no $10^{\circ}$ ano de vida, segundo a idade em meses e tipo de aleitamento no Hospital Menino Jesus - Munícipio de Sáo Paulo em 1969.

\begin{tabular}{|c|c|c|c|c|c|c|c|c|c|c|c|c|}
\hline \multirow{2}{*}{$\begin{array}{l}\text { Idade } \\
\text { meses }\end{array}$} & \multicolumn{2}{|c|}{$\begin{array}{l}\text { Aleitamento } \\
\text { natural }\end{array}$} & \multicolumn{2}{|c|}{$\begin{array}{c}\text { Aleitamento } \\
\text { misto }\end{array}$} & \multicolumn{2}{|c|}{$\begin{array}{l}\text { Leite de } \\
\text { vaca }\end{array}$} & \multicolumn{2}{|c|}{$\begin{array}{l}\text { Leite em } \\
\text { pó }\end{array}$} & \multicolumn{2}{|c|}{ Outros } & \multicolumn{2}{|c|}{ Total } \\
\hline & N.o & $\%$ & N. ${ }^{\circ}$ & $\%$ & N.० & $\%$ & N.o & $\%$ & N. 0 & $\%$ & N. $0^{\circ}$ & $\%$ \\
\hline $6 \mid-12$ & 35 & 6,69 & 35 & 6,69 & 25 & 4,78 & 424 & 81,07 & 4 & 0,77 & 523 & 100 \\
\hline $01-6$ & 4 & 2,78 & 2 & 1,39 & 18 & 12,50 & 117 & 81,25 & 8 & 2,08 & 144 & 100 \\
\hline Total & 89 & 5,85 & 37 & $\mathbf{5 , 5 5}$ & 43 & 6,44 & 541 & 81,11 & 7 & 1,05 & 667 & 100 \\
\hline
\end{tabular}

a) inferioridade acentuada do aleitamento natural exclusivo $(6,69 \%)$ em relação à soma de todos os tipos de aleitamento artificial, com $86,62 \%(4,78 \%+$ $81,07 \%+0,77)$ e do aleitamento misto $(6,69 \%)$, com total igual a $93,31 \%$;

b) preponderância do aleitamento artificial de todos os tipos $(86,62 \%)$ sobre a soma do percentual do aleitamento natural $(6,69 \%)$ mais o aleitamento misto $(6,69 \%)$, com total igual a $13,38 \%$;

c) preponderância do aleitamento por leite em pó $(81,07 \%)$ sobre todos os outros tipos de aleitamento artificial, ou seja: leite de vaca $(4,78 \%)$ e outros $(0,77 \%)$.
Com os dados da Tabela 2 referentes ao período de $0-6$ meses, foi construída a Figura 1.

Examinando os dados da mesma Tabela, referentes ao aleitamento no segundo semestre, vê-se que o aleitamento natural cai ao nível de $2,78 \%$, e o aleitamento misto ao de $1,39 \%$.

A queda do aleitamento natural, examinado o fenômeno no seu aspecto qualitativo, seria previsível, dentro dos princípios dietéticos do primeiro ano de vida. Essa queda não foi porém acompanhada por um aumento proporcional, também previsível, do aleitamento misto, o qual, dentro dos mesmos princípios dietéticos, deveria se sobrepor não 
ROSENBURG, O. - Aleitamento no primeiro ano de vida de crianças internadas em hospital assistencial do município de Såo Paulo, Brasil. Rev. Saúde públ., S. Paulo, 7:381-8, 1973.



Leite dẹ vaca

IPI Aleitamento misto

Aleitamento natural

Leite en pó

Fig. 1 - Tipos de aleitamento em crianças de 0 - 6 meses - 1969 Municipio de š̃o Paulo - Hospital Menino Jesus.

só ao aleitamento natural, como a todos os demais tipos de aleitamento, no segundo semestre de vida. Deve ser sa. lientado esse aspecto da questão, porque é regra universalmente aceita que o leite materno deva fazer parte do regime alimentar da criança, em maior ou menor quota, durante todo o decorrer do primeiro ano de vida. Essa regra se torna particularmente importante nas frações populacionais em que as condições de vida são precárias e para as quais a segurança de um regime lácteo articicial bem conduzido, praticamente não existe.

Voltando ao exame dos dados, sob o ponto de vista quantitativo, torna-se patente que apenas $4,17 \%$ dos lactentes, no segundo semestre de vida $(2,78 \%$ aleitamento natural $+1,39 \%$ aleitamento mis- to) recebem algumas quotas de leite materno, situação essa mais grave do que no primeiro semestre, em que $13,38 \%$ $(6,69 \%$ aleitamento natural $+6,69 \%$ aleitamento misto) das crianças ainda dele se beneficiavam.

No ano de 1972, considerado individualmente, os comentários podem ser reproduzidos de maneira idêntica ao ano de 1969, observandos-e a devida modificação no valor dos números.

O exame da Tabela 3, referente ao tipo de aleitamento de $0-12$ meses revela:

a) preponderância do aleitamento artificial de todos os tipos, com $91,97 \%$ $(8,84 \%+82,33 \%+0,80 \%)$, sobre a soma do percentual do aleitamento natural $(3,61 \%)$ e do aleitamento misto $(4,42 \%)$, com total igual a $8,03 \%$;

b) inferioridade marcante do aleitamento natural exclusivo $(3,61 \%)$ em relação à soma de todos os tipos de aleitamento artificial $(91,97 \%)$ mais aleitamento misto $(4,42 \%)$, com total igual a $96,39 \%$;

c) preponderância do aleitamento artificial por leite em pó $(82,33 \%)$ sobre todos os outros tipos de aleitamento artificial: leite de vaca $(8,84 \%)$ e outros $(0,80 \%)$.

Quanto à Tabela 4, no que se refere ao aleitamento no primeiro semestre, os resultados foram os seguintes:

a) inferioridade acentuada do aleitamento natural exclusivo $(4,81 \%)$, em relação à soma de todos os tipos de aleitamento artificial $(90,37 \%)$ e do aleitamento misto $(4,81 \%)$, com total igual a $95,18 \%$; 
ROSENBURG, O. - Aleitamento no primeiro ano de vida de crianças internadas em hospital assistencial do municíplo de São Paulo, Brasil. Rev. Saúde públ., S. Paulo, 7:381-8, 1973.

b) preponderância do aleitamento artificial de todos os tipos $(90,37 \%)$ sobre a soma do percentual do aleitamento natural $(4,81 \%)$ mais o aleitamento misto $(4,81 \%)$, com total igual a $9,62 \%$;

c) preponderância do aleitamento por leite em pó $(83,42 \%)$ sobre todos os outros tipos de aleitamento artificial, ou seja: leite de vaca $(6,95 \%)$ e outros (zero).

Com os dados da Tabela 4, referentes ao período de $0 \mid-6$ meses, foi construida a Figura 2.

T A B EL A 3

Número e porcentagem de crianças no $1 .^{\circ}$ ano de vida segundo a idade em meses e tipo de aleitamento no Hospital Menino Jesus - Município de São Paulo - 1972.

\begin{tabular}{|c|c|c|c|c|c|c|c|c|c|c|c|c|c|}
\hline \multirow{2}{*}{\multicolumn{2}{|c|}{$\begin{array}{l}\text { Idade } \\
\text { meses }\end{array}$}} & \multicolumn{2}{|c|}{$\begin{array}{c}\text { Aleitamento } \\
\text { natural }\end{array}$} & \multicolumn{2}{|c|}{$\begin{array}{l}\text { Aleitamento } \\
\text { misto }\end{array}$} & \multicolumn{2}{|c|}{$\begin{array}{l}\text { Leite de } \\
\text { vaca }\end{array}$} & \multicolumn{2}{|c|}{$\begin{array}{c}\text { Leite em } \\
\text { po }\end{array}$} & \multicolumn{2}{|c|}{ Outros } & \multicolumn{2}{|c|}{ Total } \\
\hline & & N. ${ }^{\circ}$ & $\%$ & N. 0 & $\%$ & N. ${ }^{\circ}$ & $\%$ & N. 0 & $\%$ & N.o & $\%$ & N..$^{\circ}$ & $\%$ \\
\hline $01-$ & 1 & 6 & 23,07 & 1 & 3,85 & 1 & 3,85 & 18 & 69,23 & - & - & 26 & 100 \\
\hline $11-$ & 2 & 1 & 3,33 & 3 & 10,00 & 3 & 10,00 & 23 & 76,67 & - & - & 30 & 100 \\
\hline $21-$ & 3 & 1 & 2,27 & 4 & 9,09 & 5 & 11,37 & 34 & 77,27 & - & 一 & 44 & 100 \\
\hline $31-$ & 4 & - & - & 1 & 3,12 & 2 & 6,25 & 29 & 90,63 & - & - & 32 & 100 \\
\hline $41-$ & 5 & 1 & 3,12 & 一 & - & 1 & 3,12 & 30 & 93,76 & - & - & 32 & 100 \\
\hline $51-$ & 6 & - & - & - & - & 1 & 4,35 & 19 & 95,65 & - & - & 23 & 100 \\
\hline $61-$ & 7 & - & - & - & - & 1 & 5,00 & 19 & 95,00 & - & - & 20 & 100 \\
\hline $71-$ & 8 & - & - & 1 & 9,09 & 2 & 18,18 & 7 & 63,64 & 1 & 9,09 & 11 & 100 \\
\hline $81-$ & 9 & - & - & 1 & 7,69 & 3 & 23,08 & 9 & 69,23 & - & - & 13 & 100 \\
\hline $91-$ & 10 & - & - & - & - & 1 & 14,29 & 6 & 85,71 & - & - & 7 & 100 \\
\hline 10 i一 & 11 & - & - & - & - & 1 & 16,67 & 4 & 66,66 & 1 & 16,67 & 6 & 100 \\
\hline $11 /-$ & 12 & - & - & - & - & 1 & 20,00 & 4 & 80,00 & - & - & 5 & 100 \\
\hline TOTA & & 9 & 3,61 & 11 & 4,42 & 22 & 8,84 & 205 & 82,33 & 2 & 0,80 & 249 & 100 \\
\hline
\end{tabular}

Examinando os dados da mesma Tabela, no que se refere ao aleitamento no segundo semestre, vê-se que o aleitamento natural cai ao nivel de zero e o aleitamento misto a $3,23 \%$.

Apenas $3.22 \%$ dos lactentes no segundo semestre de vida (zero aleitamento nanatural $+3,23 \%$ aleitamento misto) recebem alguma quota de leite materno.

Analisados individualmente cada um dos anos em questão, resta fazer um estudo comparativo entre os mesmos. 
ROSENBURG, O. - Aleitamento no primeiro ano de vida de crtanças internadas em hospital assistenctal do município de Săo Paulo, Brasil. Rev. Saúde públ., S. Paulo, 7:381-8, 1973.

TA B I I A 4

Número e porcentagem de crianças no $1 .^{\circ}$ ano de vida segundo tipo de aleitamento no Hospital Menino Jesus - Município de sáo Paulo - 1972.

\begin{tabular}{|c|c|c|c|c|c|c|c|c|c|c|c|c|}
\hline \multirow{2}{*}{$\begin{array}{l}\text { Idade } \\
\text { meses }\end{array}$} & \multicolumn{2}{|c|}{$\begin{array}{c}\text { Aleitamento } \\
\text { natural }\end{array}$} & \multicolumn{2}{|c|}{$\begin{array}{c}\text { Aleitamento } \\
\text { misto }\end{array}$} & \multicolumn{2}{|c|}{$\begin{array}{l}\text { Leite de } \\
\text { vaca }\end{array}$} & \multicolumn{2}{|c|}{$\begin{array}{l}\text { Leite em } \\
\text { pó }\end{array}$} & \multicolumn{2}{|c|}{ Outros } & \multicolumn{2}{|c|}{ Total } \\
\hline & N.० & $\%$ & N.० & $\%$ & N. ${ }^{\circ}$ & $\%$ & N. ${ }^{\circ}$ & $\%$ & N.o & $\%$ & N. ${ }^{\circ}$ & $\%$ \\
\hline $01-6$ & 9 & 4,81 & 9 & 4,81 & 13 & 6,95 & 156 & 83,42 & - & - & 62 & 100 \\
\hline $61-12$ & - & - & 2 & 3,23 & 9 & 14,51 & 49 & 79,03 & 2 & 3,23 & 187 & 99,99 \\
\hline TOTAL & 9 & 3,61 & 11 & 4,42 & 22 & 8,84 & 205 & 82,33 & 2 & 0,80 & 249 & 100 \\
\hline
\end{tabular}



a) no primeiro mês de vida, os percentuais se mantêm praticamente iguais, em relação ao aleitamento natural, ou seja, $23,21 \%$ para 1969 e $23,07 \%$ para 1972;

b) acentua-se a preponderância do aleitamento artificial de todos os tipos $(91,97 \%)$ em 1972, em relação ao ano de $1969(88,60 \%)$;

c) aumenta a inferioridade do aleitamento natural exclusivo $(3,61 \%)$ em 1972, em relação ao ano de 1969 $(5,85 \%)$;

d) é maior a preponderância do aleimento artificial por leite em pó em $1972(82,23 \%)$ do que em 1969 $(81,11 \%)$.

Quanto às Tabelas n. 2 e 4, no que se refere ao aleitamento no primeiro semestre, da comparação resultou:

a) acentua-se a inferioridade do aleitamento natural exclusivo no ano de $1972(4,81 \%)$ em relação ao ano de $1969(6,69 \%)$;

Fig. 2 - Tipos de aleitamento em crianças de 0 - 6 meses - 1972 - Municíplo de São Paulo - Hospital Menino Jesus.

b) acentua-se a preponderância do aleitamento artificial de todos os tipos (90,37\% para 1972 e $86,62 \%$ para 1969$)$ sobre a soma dos percentuais do aleitamento natural mais o aleitamento misto; 
ROSFNBURG, O. - Aleitamento no primeiro ano de vida de crianças internadas em hospital assistencial do município de São. Paulo, Brasiḷ. Rev. Saúde públ., S. Paulo, 7:381-8, 1973.

c) acentua-se a preponderância do aleitamento artificial por leite em pó $(83,42 \%$ para 1972 e $81,07 \%$ para 1969) sobre todos os outros tipos de aleitamento artificial - leite de vaca e outros.

Examinando os dados das Tabelas 2 e 4 referentes ao aleitamento no segundo semestre, pode-se observar:

a) o aleitamento natural cai para zero em 1972, enquanto estava ao nívei de 2,78\% em 1969. Entretanto, o aleitamento misto sobe para $3,23 \%$ em 1972, enquanto estava ao nível de $1,39 \%$ em 1969 ;

b) no segundo semestre de vida, em 1972 , apenas $3,23 \%(0+3,23 \%)$ dos lactentes recebem alguma quota de leite materno, enquanto em 1969, $4,17 \%(2,78+1,39)$ ainda dele se beneficiavam.

\section{COMENTARIOS}

Aceitando como indiscutível a predominância do aleitamento artificial sobre o aleitamento natural, e o quase total abandono deste último já no primeiro semestre de vida, fenômeno esse constatado na prática, e do qual a pesquisa acima pode dar alguma expressão numérica, no que se refere às classes menos favorecidas, cabem aqui certas considerações sobre alguns aspectos do problema.

Desnecessário se torna repisar as ciesvantagens do aleitamento artificial de qualquer espécie sobre a alimentação ao seio, em particular nas classes sociais de escasso rendimento econômico, tal como a que forneceu amostra para o estudo. Entretanto, verifica-se que, já no primeiro semestre, é baixíssimo o percentual de crianças que dela se beneficiam.

Vê-se, também, que o uso do leite em pó como substituto do leite humano já assumiu, nas camadas mais pobres da população, dimensões consideráveis. $\mathbf{E}$ a generalização do processo decorre de inúmeros fatores, entre outros, da propaganda, da industrialização, da urbanização, como também do hábito já estabeleciđo de se fazer a distribuição gratuita do leite nas maternidades e nos diferentes locais de atendimento ao lactente. A oferta de uma lata desse alimento à mãe pobre pode resultar num estímulo para o abandono da alimentação natural. Ao mesmo tempo, o leite doado à criança, raramente, ou nunca, satisfaz as suas necessidades alimentares. Mas quando o hábito de receber já se estabeleceu, e quando, além desse hábito, existe o fator agravante do escasso poder aquisitivo para uma quota complementar do alimento, o resultado, para a criança, é a desnutrição.

Em relação a esse tópico, é interessante reproduzir, literalmente, CHaSe 1 (1970): "Quando quotas suplementares de leite são distribuidas às crianças, a frequiência da alimentação ao peito diminui. Além disso, o suplemento é dado, em grande parte, às crianças mais velhas, levando a mais nova à subnutrição, numa idade mais precoce."

Quanto à época do desmame, dentro do pequeno número de crianças que ainda são amamentadas ao seio, verifica-se que ela é precocíssima para a maioria delas.

Em apoio a essa tese, pode-se citar o fato de que, de $23,21 \%$ e $23,07 \%$ de criancas aleitadas exclusivamente ao seio, no primeiro mês de vida, em 1969 e 1972, o percentual cai bruscamente para $4,06 \%$ e $3,33 \%$ respectivamente, do primeiro para o segundo mês.

Tal fato, associado ao da escassez do alimento substitutivo, que de mês para mês vai sendo exigido em volumes maio- 
ROSENBURG, O. - Aleitamento no primeiro ano de vida de crianças internadas em hospital assistencial do municiplo de 8å Paulo, Brasil. Rev. Saúde públ., S. Paulo, 7:381-8, 1973.

res, explica a evolução gradual para as formas mais graves de desnutrição, já no primeiro ano de vida 2 , formas essas que, quanto mais precoce o desmame, tanto mais cedo atingirão a sua culminância

RSPU-B/191

RosenbURG, O. - [Lacteal feeding, in the first year of lite, of children admitted to an assistential hospital of S. Paulo City, Brazil]. Rev. Saúde públ., S. Paulo, 7:381-8, 1973 .

SUmmary: The study of the kind of lacteal feeding of 667 and 294 children admitted to an Assistential Hospital of S. Paulo City in 1969 and 1972, showed a reduction of breast feeding, in the first year of life, from $5.84 \%$ in 1969 to $3.61 \%$ in 1972 , and of mixed feeding from $5.54 \%$ to $4.41 \%$. In the fist semester of life, the dropping of breast feeding was from $6.69 \%$ in 1969 to $4.81 \%$ in 1972 , the same occurring with mixed feeding. In 1969 , breast feeding decreased from $23.21 \%$ in the first month to $4.06 \%$ in the secand month, and in 1972, from 23.07\% in the first month to $3.33 \%$ in the second month. The frequency of artificial feeding on powdered milk raised from $81.10 \%$ in 1969 to $82.32 \%$ in 1972. vices*.

UNITERMS: Lactation*; Hospital, pediatric*; Community health ser-

\section{REFERENCIAS BIBLIOGRAFTCAS}

1. CHASE, H. P. \& MARTIN, H. P. - Undernutrition and development. New Eng. J. Med., 282:933-9, 1970.

2. ROSENBURG, O. - o estado de nutrigáo de crianças internadas por todas as causas em Hospital Assistencial do Municíplo de săo Paulo. Rev. Saúde pribl., S. Paulo, 5:77-81, 1971.

Recebido para publicaçđo em 17-9-1973

Aprovado para publicaçăo em 9-10-1973 